\title{
Understanding the effect of resident duty hour reform: a qualitative study
}

\author{
Peter E. Wu MD, Lynfa Stroud MD MEd, Heather McDonald-Blumer MD MSc, Brian M. Wong MD
}

See CMAJ: editorial, www.cmaj.ca/lookup/doi/10.1503/cmaj140588; and analysis, www.cmaj.ca/lookup/doi/10.1503/cmaj.131053

\section{Abstract}

Background: Concern surrounding the effect of resident fatigue on patient care recently led the National Steering Committee on Resident Duty Hours to publish Canadian recommendations suggesting that duty periods of 24 or more consecutive hours without restorative sleep should be avoided. We sought to characterize how different training programs are preparing for the effect of such changes on education, patient care and provider well-being.

Methods: Using constructivist grounded theory methodology, we conducted 18 one-on-one semistructured interviews with program directors, division directors and department chiefs from 11 residency programs affiliated with one Canadian medical school. We gathered and analyzed data iteratively until we reached theoretical saturation.

Results: The key theme articulated by our participants was that changes in resident duty hours would potentially lead to gaps in the provision of clinical care. These changes affect acute care specialties based primarily in the inpatient setting (e.g., medicine, surgery) more than primarily ambulatory (e.g., family medicine) or shift-model based (e.g., emergency) specialties. Potential strategies to address gaps in clinical care include resident-based solutions, faculty-based solutions and solutions based on other providers (e.g., nonacademic physicians, physician extenders). Each solution has unique advantages and disadvantages in terms of education, continuity of care, preparedness for practice and provider well-being.

Interpretation: Our data-driven framework serves as a guide for programs to anticipate challenges of satisfying clinical care needs in the face of changes to resident duty hours, while balancing education, care continuity, preparedness for practice and provider wellbeing. Our findings challenge the "one-size-fits-all" approach to changes to resident duty hours and endorse flexibility in enacting duty hour regulations based on specialty-specific factors.

oncerns about resident fatigue affecting patient safety have prompted regulatory changes limiting resident duty hours in Canada and the United States. ${ }^{1-3}$ In response to a grievance filed in the province of Quebec on the basis that 24-hour shifts violate the Canadian Charter of Rights and Freedoms, ${ }^{1}$ postgraduate training programs in Quebec have implemented 16-hour maximum workdays for all trainees. ${ }^{1}$ Recently, the National Steering Committee on Resident Duty Hours in Canada called for a comprehensive approach to minimize resident fatigue and recommended that "duty periods of twenty four or more consecutive hours without restorative sleep should be avoided." ${ }^{4}$ Therefore, changes to resident duty hours similar to those in Quebec may eventually apply to residency training programs across Canada.

There are little data available regarding changes to resident duty hours in the Canadian context, and much of the research on the effect of these changes comes from US studies. These studies yielded mixed results about the effect of changes to duty hours on patient outcomes and residents' quality of life and education. Some studies suggested improvements in patient care and the well-being of residents, ${ }^{5-7}$ whereas others suggested deleterious effects on continuity of care, ${ }^{8}$ residents' quality of life, and the educational experience in some training disciplines. ${ }^{9,10}$ None provided conclusive evidence that a reduction in resident duty hours led to increased sleep by residents ${ }^{11,12}$ or improvements in educational or patient safety outcomes. ${ }^{13-15}$ The available evidence is limited because most studies consider the effect on different programs in isolation rather than in comparison to other disciplines. Moreover,

Competing interests: Peter Wu was a resident representative on the Survey Development Working Group of the National Steering Committee on Resident Duty Hours.

This article has been peer reviewed.

Correspondence to: Peter Wu, pete.wu@mail.utoronto.ca

CMAJ Open 2014.DOI:10.9778/cmajo.20130049 
most of the studies used surveys to assess the perceptions of trainees and faculty; these surveys often provide insufficient detail to explore and characterize the nuanced effect of reducing resident duty hours and the interplay of the factors affected by these reductions. As a result, it is difficult to predict how all of the factors relate to one another, leaving program directors with the challenge of applying a generic understanding of the various effects of reductions of resident duty hours to their specific training contexts. To help program directors anticipate these problems and proactively identify solutions, we aimed to explore the perceived effect of changes to resident duty hours from the perspective of program directors, division directors and department chiefs, and to explore how they planned to address changes in resident duty hours.

\section{Methods}

We used constructivist grounded theory, a qualitative methodology that facilitates the inductive development of a data-driven theoretical framework to describe a social phenomenon. We specifically chose this approach because it allowed us to incorporate what is generally known about the effect of restrictions of resident duty hours taken from prior research and to sensitize our inductive analysis of the data. ${ }^{16-20}$ We aimed to develop a theoretical framework to help program directors anticipate the potential effects of changes to resident duty hours on individual training programs. The University of Toronto Research Ethics Board approved this study.

\section{Study participants and setting}

Eligible participants included program directors, division directors and department chiefs associated with residency programs at the University of Toronto. We sampled purposively to include a balance of medical, surgical and other training programs; primarily hospital-based, primarily ambulatorybased and shift-model based programs; and large and small programs. In balancing these program features, we hoped to better understand how changes in resident duty hours might affect a wide range of residency program types. We performed confirming-disconfirming snowball sampling (a method that entails seeking out participants who might have similar or differing viewpoints) to identify additional key participants. Specifically, we used theoretical sampling to look for participants with different academic roles working within specialties with different practice patterns.

Postgraduate Medical Education at the University of Toronto comprises more than 3000 trainees among 17 departments, with 27 affiliated teaching sites. The postgraduate programs with the largest numbers of trainees are internal medicine (512), surgery (516), family medicine (390) and pediatrics (389). ${ }^{21}$

As of July 2013 (at the time of the study), the terms and conditions of employment of residents in Ontario teaching hospitals as per the PAIRO-CAHO (Professional Association of Internes and Residents of Ontario-Council of Academic Hospitals of Ontario) agreement limited in-hospital overnight calls to a maximum of 1 in 4 nights and a maximum number of consecutive work hours to 24 with a crossover period meant for adequate patient care handover. ${ }^{22}$

\section{Data collection and analysis}

The principal investigator (P.E.W.) conducted one-on-one interviews using a semistructured, open-ended interview guide with probes as needed (Appendix 1, www.cmajopen.ca/content /2/2/E115/suppl/DC1). We formulated the interview script based on key topics surrounding resident duty hours that were prevalent in the literature at the time. We piloted the initial script with 2 participants and revised it based on their feedback; thereafter the research team iteratively adjusted it based on concurrent data analysis for subsequent interviews. We asked participants to speak about key topics regarding duty hour changes and used probes where necessary to confirm or challenge prior themes and to identify new themes.

We audiotaped, anonymized and transcribed interviews verbatim. Three members of the research team (P.E.W., L.S. and B.M.W.) conducted data analysis concurrently with data gathering; they used the constant comparative method to identify emerging themes and to make iterative adjustments to the coding structure. This process also helped to determine when we had reached theoretical saturation (the point at which no new themes emerged from the data). ${ }^{23}$ Our analysis was reflexively mindful of our own subject positions in the research context; we remained cognizant of the factors (e.g., our types of clinical practice, stages of career, academic interests, educational leadership positions) that may have affected our analysis of the data. We also fostered reflexivity by including multiple team members with different subject positions, and used confirming-disconfirming sampling to purposively challenge our interpretations of the data as they emerged.

\section{Results}

The study included 18 participants comprising 13 program directors, 2 division directors and 3 department chiefs. Participants were associated with a variety of training programs: internal medicine and pediatrics $(n=6)$; general, vascular and orthopedic surgery $(n=4)$; family medicine $(n=2)$; radiology $(n=1)$; psychiatry $(n=1)$; obstetrics and gynecology $(n=1)$; anesthesia $(n=1)$; and emergency medicine $(n=2)$. All eligible participants whom we invited agreed to participate. To ensure anonymity, we refer to representative quotations as "Med-Peds" (Internal Medicine and Pediatrics), "Surgical," or "Other" faculty. We also do not indicate whether the respondent was a program director, division director or department chief.

We identified 5 key areas where participants perceived an effect of changes to resident duty hours: 1) clinical care provision; 2) education; 3) preparedness for practice; 4) continuity of care; 5) provider well-being. However, participants felt that these areas were only affected if changes to resident duty hours resulted in a gap in clinical care provision, which made this the central theme.

Respondents from acute care, inpatient-based training programs (e.g., internal medicine, surgery) expressed far greater concerns than respondents from shift-based or primarily 
ambulatory specialties about the potential clinical care gaps created by duty hour changes because these specialties require in-hospital physician coverage at all times (Box 1).

In contrast, primarily ambulatory and shift-based programs (e.g., family medicine, emergency medicine, psychiatry) typically require less than 16 consecutive hours of physician coverage, such that respondents from these specialties tended to view changes to resident duty hours as having a lesser effect (Box 1).

The choice of potential solution also depended on the degree to which changes to resident duty hours affected clinical care provision, which varied substantially depending on the specialty and the nature of their clinical care demands (Figure 1). As such, no "one-size-fits-all” solution exists (Box 1).

Our respondents' anticipated strategies to address the gaps in clinical care provision created by changes to resident duty hours can be understood as 3 broad categories: resident-based solutions, academic faculty-based solutions and alternative workforce-based solutions (Figure 1). Each strategy has its respective advantages and disadvantages in terms of its effect on the other 4 areas identified as being affected by changes to duty hours (i.e., education, preparedness for practice, continuity of care and provider well-being).

\section{Resident-based solutions}

This first set of solutions involves either redistributing the working hours of the current number of residents or increasing the overall number of residents to maintain adequate physician

\section{Box 1: Perceived effects of changes to resident duty hours}

"Restructuring of the entire call schedule ... would force a reexamination of how residents are allocated and how services are covered at night." Med-Peds faculty - Respondent 2

"It's rare that [residents] would work a 16-hour day in [our specialty] ... As I say, this hasn't really been a topic of conversation in [our specialty] very much." Other faculty - Respondent 11

"It's obvious to me that it's not one size fits all ... I think that it's a complete fallacy to think that the training needs and requirements of a family doctor are the same as for a neurosurgeon." Surgical faculty - Respondent 7 coverage of clinical services. Either way, these solutions likely result in more shifts of shorter duration for residents (Box 2).

Participants thought that resident-based strategies would adversely affect the educational experience, preparedness for practice and continuity of patient care, and worried that shorter shifts might lead to decreased exposure to clinical cases and missed learning opportunities for trainees (Box 2). Switching to shorter resident shifts would also disrupt continuity of care in models of continuous physician coverage by fragmenting resident-delivered care and leading to increased patient handovers and possibly a loss of patient ownership among trainees (Box 2).

Although respondents acknowledged that increasing resident numbers might avoid some concerns associated with redistributing resident work hours, they felt that this solution could lead to an overproduction of graduating specialists in a job market where opportunities are already limited in some specialties (Box 2).

The potential advantages of resident-based strategies from the perspective of the participants were that they did not increase clinical workload for academic faculty and would allow them to dedicate their time to education and research.

\section{Academic faculty-based solutions}

The second set of solutions involves increasing the clinical workload of attending staff to fill gaps in clinical care created by restrictions to resident duty hours. For surgical specialties in particular, participants felt that this may be necessary owing to the highly specialized nature of their clinical work (Box 3 ).

Respondents perceived that this option would substantially affect provider well-being (in this case, the provider being academic faculty). If resident duty hours were changed, attending staff from academic institutions would need to provide more front-line clinical care to do work previously done by residents. This might be particularly difficult for early-stage academic faculty, who would have transitioned from having work-hour restrictions as a resident to having no restrictions as a staff physician (Box 3).

Participants worried about how this would affect the multiple other responsibilities that they had, including educational

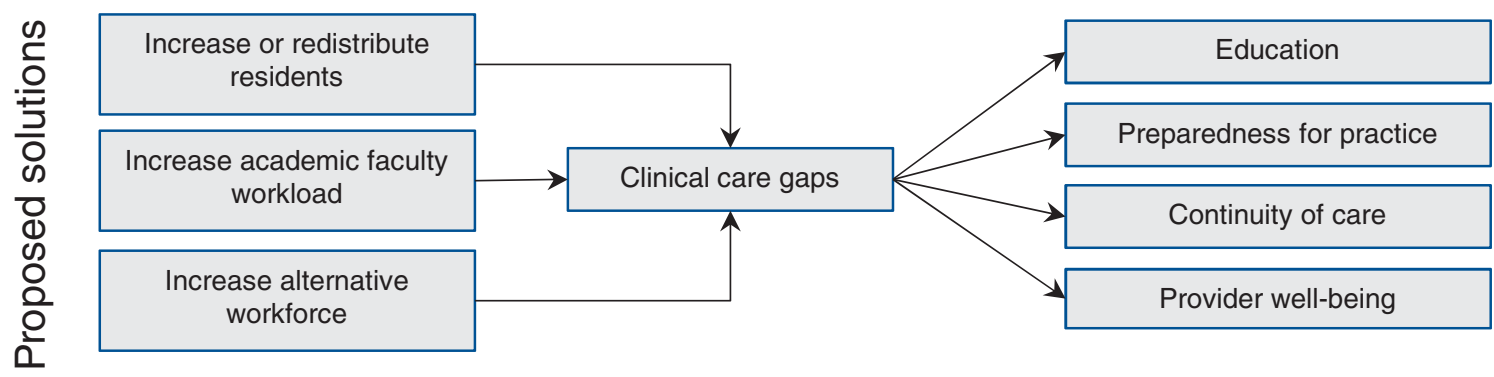

Figure 1: Framework linking 5 key areas of impact identified from study data. Participants perceived clinical care gaps to be the central theme affected by changes to resident duty hours. Participants discussed 3 sets of solutions to address clinical care gaps, which in turn will affect education, preparedness for practice, continuity of care and provider well-being. 
roles that might negatively affect resident education (Box 3). These potential negative effects may also have later consequences with respect to retaining or recruiting staff to academic practice (Box 3).

\section{Alternative workforce-based solutions}

The third set of solutions includes hiring international fellows, nonacademic physicians or physician extenders (e.g., nurse practitioners, physician assistants) to help to deliver clinical care (Table 1).

Hiring of nonacademic physicians, such as a general internist to cover consults in the emergency department or to provide

\section{Box 2: Resident-based solutions}

"You essentially take existing resources and spread them around or you can put more resources into the system." Med-Peds faculty - Respondent 3

"... [W]ill [the residents] be having an adequate exposure to the number of cases and the case volumes and the variety that they will need?" Surgical faculty - Respondent 8

"There's no question that following someone from admission to discharge and into the outpatient setting is ... the optimal experience in terms of seeing the natural progression of illness..." Med-Peds faculty - Respondent 4

"The number of different handovers that are going to be involved in safely managing patients and all the consequences of those handovers may have impact on patient outcomes and safety." Med-Peds faculty - Respondent 4

"I think that that sense of, 'l'll do whatever is necessary to take care of my patients,' will be weakened." Med-Peds faculty - Respondent 3

"I know we're graduating too many residents, but for service provision, we've got to keep it as it is right now." Surgical faculty - Respondent 7

\section{Box 3: Academic faculty-based solutions}

"My chief concern is the availability of senior residents. We need high level help ... I will personally, as will the other staff, have to be prepared if we're around with a junior resident to do more hands-on supervision." Surgical faculty - Respondent 8

"... [N]o one will protect the staff in the way that the residents are protected, and there's going to have to be a cultural shift with the 16-hour shift that applies more than just to the residents for it to be really successful and endorsed, because otherwise it will just be shifted on to another group out of necessity." Surgical faculty — Respondent 8

"People go into academics primarily for 2 reasons. One is that they like to teach .... and the other is that they like to ... research. ... If you find that you're teaching less and have less time for academic work, then ... the reason for going into academics will become less compelling, less attractive." Med-Peds faculty Respondent 3

"If it made academic life significantly less appealing or enjoyable it would reduce the number of people who go into academics." MedPeds faculty - Respondent 3 ward-based clinical care, was seen as a potential solution for medical specialties. However, participants representing surgical specialties did not feel that hiring additional nonacademic staff would be feasible because institutions contractually allocate access to operating room facilities to surgeons (Box 4).

The advantage of hiring additional health practitioners is that these solutions do not increase the workload of residents or academic faculty, improving both faculty and trainee wellbeing, albeit potentially at the expense of the well-being of the additional health practitioners depending on the solution. For instance, international fellows may not be protected by the same local regulations for resident duty hours. ${ }^{24}$ Therefore, this may simply shift excess workload to another group who will then battle issues of fatigue and well-being (Box 4).

Participants felt that the effect on education would be mixed. On the positive side, academic faculty would not increase their clinical work and could dedicate more time to educational activities. However, by assigning clinical work to other health care providers, there again may be less clinical exposure, leading to disadvantages from an educational and preparedness standpoint. In particular, respondents from the surgical program worried that by assigning ward-based patient care to other health care providers, surgical trainees would view this aspect of their clinical work as less important and would not be prepared for this element of their practice (Box 4). The other important consideration was that this specific set of solutions would require additional funding (Box 4).

\section{Interpretation}

Our study findings suggest that a central factor that program directors, division directors and department chiefs consider when anticipating the implications of restrictions on resident duty hours is the effect on delivery of clinical services. Participants felt that reductions of resident duty hours will more substantially affect programs that are heavily inpatient-based, a phenomenon that has not generally received much attention.

Table 1: Description of clinical workforce

\begin{tabular}{|ll|}
\hline Title & \multicolumn{1}{c|}{ Description } \\
\hline Residents & $\begin{array}{l}\text { Medical doctors in a graduate training program, } \\
\text { practising under the supervision of fully licensed } \\
\text { physicians. }\end{array}$ \\
\hline $\begin{array}{l}\text { Academic } \\
\text { faculty }\end{array}$ & $\begin{array}{l}\text { Fully licensed physicians with a university } \\
\text { appointment and academic focus. } \\
\text { Responsibilities include supervision of residents. }\end{array}$ \\
\hline $\begin{array}{l}\text { International } \\
\text { fellows }\end{array}$ & $\begin{array}{l}\text { Advanced trainees who have often completed } \\
\text { training in another accredited system. } \\
\text { Supervised by academic faculty. }\end{array}$ \\
\hline Nonacademic \\
physicians & $\begin{array}{l}\text { Fully licensed physicians who primarily do } \\
\text { patient care with no required educational } \\
\text { responsibility. }\end{array}$ \\
\hline $\begin{array}{l}\text { Physician } \\
\text { extenders }\end{array}$ & $\begin{array}{l}\text { Nonphysicians trained to aid in clinical care. } \\
\text { Examples include physician assistants and } \\
\text { nurse practitioners. }\end{array}$ \\
\hline
\end{tabular}


As illustrated by our data-driven framework (Figure 1), our findings show important links between the effects on education, continuity of care, preparedness for practice and provider well-being that highlight specialty-specific differences. As such, it is difficult to recommend a one-size-fits-all approach to training programs to best prepare for the anticipated changes to duty hours.

Our results support findings from prior studies showing that changes to resident duty hours will have broad impacts on the educational experience, provider well-being, continuity of care and preparedness for practice. Academic health centres in the US have begun to hire additional health care workers to satisfy clinical care needs in the face of changes to resident work hours. ${ }^{25-27}$ A recent study comparing traditional call models to a model that limits first-year internal medicine residents to 16 hours found that although residents in the newer model had more sleep, they reported decreased educational opportunities, increased number of handovers and a perceived decrease in quality of care. ${ }^{9}$ As well, survey studies in both Canada and the US among general surgery residents showed self-reported poorer quality of life, decreased continuity of care and educational experiences associated with implementation of duty-hour restrictions. ${ }^{28,29}$ Similarly, studies from Europe suggest a perceived decrease in quality of care $^{30}$ and decreased operative experience ${ }^{31}$ since the implementation of the European Working Time Directive. Our study provides a Canadian perspective on this topic, which is important because the changes being proposed in Canada differ from those in these other jurisdictions (e.g., decreasing maximum shift length to 16 hours for all training years as opposed to only for first-year residents in the US).

Furthermore, by considering the effect on clinical care delivery, the consequences for all health care providers, not just trainees, becomes more evident. Much of the published literature understandably focuses on residents, yet our respondents spoke about the impact on the well-being of academic faculty and other health care providers. This may reflect in part the fact that we interviewed department chairs, divisional directors and program directors. However, recent studies report that

\section{Box 4: Alternative workforce-based solutions}

"The hospital doesn't have additional OR [operating room] time to offer to bring on another surgeon. So, that sort of limits automatically the number of people at the consultant level. So, it is different. An internist doesn't require all this other infrastructure to do their work at night." Surgical faculty - Respondent 8

"International fellows are desperate to start with. They're a vulnerable population. This is just going to further accentuate that." Surgical faculty — Respondent 8

"I really do see a danger of fragmenting the patient's care, of not training these people to be responsible ... [When] you bring on other physician extenders and [the residents] get the message that someone else is going to be there to pick [ward care] up." Surgical faculty - Respondent 8

"... [The] increase calls for the hospital resources to fill the gap that is created by the decreased resident work hours and that's money that the hospitals don't have." Med-Peds Faculty — Respondent 3 attending staff perceived increased workloads and decreased time for teaching ${ }^{32}$ associated with changes to resident duty hours, suggesting that we need to pay attention to how these changes affect faculty as well.

\section{Limitations}

This study is limited in that it was conducted at one university centre, and the structure and coverage requirements of residency programs at the University of Toronto may be different from those in other jurisdictions. Additionally, this study examined only the perceived effects of changes to resident duty hours from the perspectives of program directors, division directors and department chiefs, as opposed to residents or other health care professionals, and is not necessarily predictive of what will happen. The framework we have derived will need to be revisited and adjusted over time as changes are made; however, ensuring appropriate delivery of clinical services is likely to remain the core issue. Also, although we believe that our framework provides useful guidance to training programs, the specific advantages and disadvantages and emphasis on the various effects will understandably differ from one context to the next. Finally, although theoretical saturation was achieved in our interviews, there is always the possibility of missing the divergent opinion of a potential participant that we did not capture.

\section{Conclusion}

Our findings support the position of the Canadian National Steering Committee on Resident Duty Hours that no one-sizefits-all solution exists to address the potential effect of restricting resident duty hours. Training needs specific to specialties and the degree to which changes to resident duty hours affect delivery of clinical care should factor more visibly into decisions as we consider next steps. Our data-driven framework serves as a guide for program directors to anticipate challenges specific to the context of the program's specialty while they attempt to optimize delivery of clinical care in the face of changes to resident duty hours.

\section{References}

1. McGill University Health Centre v. Association des Résidents de McGill (2011), Grievance No. 4-CUSM-0809-01 (Arbitrator: Jean-Pierre Lussier).

2. ACGME duty hours. Chicago (IL): Accreditation Council for Graduate Medical Education; 2011.

3. National Research Council, Institute of Medicine. Resident duty hours: enhancing sleep, supervision, and safety. Washington: National Academies Press; 2009.

4. National Steering Committee on Resident Duty Hours. Fatigue, risk and excellence towards a pan-Canadian consensus on resident duty hours. Ottawa (ON): Royal College of Physicians and Surgeons of Canada; 2013.

5. Levine AC, Adusumilli J, Landrigan CP. Effects of reducing or eliminating resident work shifts over 16 hours: a systematic review. Sleep 2010;33:1043-53.

6. Fletcher KE, Davis SQ, Underwood W, et al. Systematic review: effects of residents work hours on patient safety. Ann Intern Med 2004;141:851-7.

7. Landrigan CP, Rothschild JM, Cronin JW, et al. Effect of reducing interns' work hours on serious medical errors in intensive care units. N Engl 7 Med 2004; 351:1838-48.

8. Fletcher KE, Saint S, Mangrulkar RS. Balancing continuity of care with residents' limited work hours: defining the implications. Acad Med 2005;80:39-43.

9. Desai SV, Feldman L, Brown L, et al. Effect of the 2011 vs 2003 duty hour regulation-compliant models on sleep duration, trainee education, and continuity of patient care among internal medicine house staff: a randomized trial. $7 A M A$ Intern Med 2013;173:649-55.

10. Sen S, Kranzler HR, Didwania AK, et al. Effects of the 2011 duty hour reforms on interns and their patients: a prospective longitudinal cohort study. $7 A M A$ Intern Med 2013;173:657-62. 
11. Landrigan CP, Fahrenkopf AM, Lewin D, et al. Effects of the accreditation council for graduate medical education duty hour limits on sleep, work hours, and safety. Pediatrics 2008;122:250-8.

12. Arora VM, Georgitis E, Siddique J, et al. Association of workload of on-call medical interns with on-call sleep duration, shift duration, and participation in educational activities. $7 A M A$ 2008;300:1146-53.

13. Fletcher KE, Underwood W III, Davis SQ, et al. Effects of work hour reduction on residents' lives: a systematic review. 7AMA 2005;294:1088-100.

14. Businger AP, Laffer U, Kaderli R. Resident work hour restrictions do not improve patient safety in surgery: a critical appraisal based on 7 years of experience in Switzerland. Patient Saf Surg 2012;6:17.

15. Moonesinghe SR, Lowery J, Shahi N, et al. Impact of reduction in working hours for doctors in training on postgraduate medical education and patients' outcomes: systematic review. BMJ 2011;342:d1580.

16. Charmaz K. Constructing grounded theory: a practical guide through qualitative analysis. London (UK): SAGE Publications; 2006.

17. Charmaz K. The legacy of Anselm Strauss in constructivist grounded theory. Stud Sym In. 2008;32:127-41.

18. Strauss A, Corbin J. Basics of qualitative research: grounded theory procedures and techniques. $2^{\text {nd }}$ ed. Thousand Oaks (CA): SAGE Publications; 1998.

19. Kennedy TJ, Lingard L. Making sense of grounded theory in medical education. Med Educ 2006;40:101-8.

20. Lingard L, Albert M, Levinson W. Grounded theory, mixed methods, and action research. BM7 2008;337:a567.

21. Spadafora S. Annual report. Fuly 1, 2011-7une 30 2012. Toronto (ON): Postgraduate Medical Education, University of Toronto; 2012.

22. Professional Association of Internes and Residents of Ontario (PARO) and the Council of Academic Hospitals of Ontario (CAHO) Agreement. Available: www.myparo.ca/PARO-CAHO_Agreement (accessed 2013 Nov. 10).

23. Creswell JW. Data collection in qualitative inquiry and research design. Thousand Oaks (CA): SAGE Publications; 1998:109-135.

24. Nousiainen MT, Latter DA, Backstein D, et al. Surgical fellowship training in Canada: What is its current status and is improvement required? Can 7 Surg 2012;55:58-65.

25. Drolet BC, Khokhar MT, Fischer SA. The 2011 duty-hour requirements - a survey of residency program directors. N Engl 7 Med 2013;368:694-7.

26. Freed GL, Dunham KM, Moran LM, et al. Resident work hour changes in children's hospitals: impact on staffing patterns and workforce needs. Pediatrics 2012;130:700-4.

27. Oshimura J, Sperring J, Bauer BD, et al. Inpatient staffing within pediatric residency programs: work hour restrictions and the evolving role of the pediatric hospitalist. 7 Hosp Med 2012;7:299-303.

28. Antiel RM, Reed DA, Van Arendonk KJ, et al. Effects of duty hour restriction on core competencies, education, quality of life, and burnout among general surgery interns. 7AMA Surg 2013;148:448-55.

29. Hamadani FT, Deckelbaum D, Sauve A, et al. Abolishment of 24-hour continuous medical call duty in Quebec: a quality of life survey of general surgical residents following implementation of the new work-hour restrictions. F Surg Educ 2013; 70:296-303.

30. Edwards S. Impact of doctor working time cap on patient safety and training getting worse, says new survey [news release]. London (UK): Royal College of Surgeons of England; 2010. Available: www.rcseng.ac.uk/news/impact-of -doctor-working-time-cap-on-patient-safety-and-training-getting-worse-says-new -survey\#.Udh4LOD8HS9 (accessed 2013 Nov. 10).

31. Breen K, Hogan AM, Mealy K. The detrimental impact of the implementation of the European working time directive (EWTD) on surgical senior house officer (SHO) operative experience. Ir 7 Med Sci 2013;182:383-7.

32. Roshetsky LM, Coltri A, Flores A, et al. No time for teaching? Inpatient attending physicians' workload and teaching before and after the implementation of the 2003 duty hours regulations. Acad Med 2013;88:1293-8.

Affiliations: Department of Medicine (Wu, Stroud, McDonald-Blumer, Wong), University of Toronto; Department of Medicine (Wu), Toronto General Hospital; Department of Medicine (Stroud, Wong), Sunnybrook Health Sciences Centre; Centre for Quality Improvement \& Patient Safety (Wong), University of Toronto, Toronto, Ont.

Contributors: All of the authors contributed to the conception and design of the study, and the analysis and interpretation of the data. All of the authors drafted and revised the article, and approved the final version submitted for publication.

Acknowledgements: The authors thank Ayelet Kuper and Maria Mylopoulos for their feedback on the manuscript.

Supplemental information: For reviewer comments and the original submission of this manuscript, please see www.cmajopen.ca/content/2/2 /E115/suppl/DC1 